\title{
Oxidative Stress in Endometrial Flushing Fluid of Patients with Polycystic Ovary Syndrome, Endometrioma and Uterine Leiomyoma: Comparison with Healthy Controls
}

\author{
Mustafa DEMIR 1 , Onur INCE ${ }^{2}$, Bulent YILMAZ ${ }^{3}$, Mert Ulas BARUT ${ }^{4}$, Ulviye CANSU OZTURK³ , Avni KILIC 5 , \\ Ahmet Berkiz TURP6 ${ }^{6}$ Recep SUTCU77, Seyithan TAYSI8 \\ Gazianterp, Turkey
}

\begin{abstract}
ABSTRASCT
OBJECTIVE: Polycystic ovary syndrome, myoma uteri and endometrioma are frequently seen gynecologic problems and all three diseases may cause infertility. Aim of this cross-sectional study was to compare total antioxidant status, ceruloplasmin, total sulfhydryl, total oxidant status, lipid hydroperoxide and oxidative stress index levels in endometrial flushing fluid of patients with Polycystic ovary syndrome $(n=20)$, uterine leiomyoma $(n=20)$, endometrioma $(n=19)$, and healthy women $(n=20)$.
\end{abstract}

STUDY DESIGN: We compare endometrial flushing fluid of patients with polycystic ovary syndrome $(n=20)$, uterine leiomyoma $(n=20)$, endometrioma $(n=19)$ and healthy women $(n=20)$. Endometrial flushing fluid samples were collected during the implantation window of all women.

RESULTS: Mean age of groups was $28.90 \pm 5.45,37.25 \pm 2.73,32.84 \pm 6.62$ and $32.15 \pm 5.18$ in Polycystic ovary syndrome, myoma uteri, endometrioma and control groups, respectively $(p<0.05)$. Mean total antioxidant status, ceruloplasmin and total sulfhydryl levels indicating antioxidant state were comparable between Polycystic ovary syndrome, myoma uteri, endometrioma and control groups ( $p=0.806$, $p=0.156, p=0.328$ respectively for markers). Similarly, oxidant state-related markers didn't differ significantly between 4 groups ( $p=0.090$ for total oxidant status, $p=0.087$ for lipid hydroperoxide, $p=0.312$ for oxidative stress index).

CONCLUSION: Endometrial flushing fluid total antioxidant status, total oxidant status, lipid hydroperoxide, ceruloplasmin, and total sulfhydryl levels during implantation window didn't differ between women with Polycystic ovary syndrome, uterine leiomyoma, endometrioma, and healthy controls.

Keywords: Endometrial flushing fluid oxidative stress, Endometrial receptivity, Endometrioma, Myoma uteri, Polycystic ovary syndrome

Gynecol Obstet Reprod Med 2020;26(2):123-129

${ }^{1}$ Department of Obstetrics and Gynecology, Izmir Katip Celebi University Faculty of Medicine, Izmir, Turkey

2 Department of Obstetrics and Gynecology, Kutahya Health Science University Faculty of Medicine, Kutahya, Turkey

3 Department of Obstetrics and Gynecology, Recep Tayyip Erdogan University Faculty of Medicine, Rize, Turkey

${ }^{4}$ Department of Obstetrics and Gynecology, Harran University Faculty of Medicine, Sanliurfa, Turkey

5 Department of Obstetrics and Gynecology, Sanliurfa Education and Research Hospital, Sanliurfa, Turkey

${ }^{6}$ Department of Obstetrics and Gynecology, Silifke State Hospital, Mersin, Turkey

Department of Biochemistry, Izmir Katip Celebi University Faculty of Medicine, Izmir, Turkey

${ }^{8}$ Department of Biochemistry, Gaziantep University, Faculty of Medicine, Gaziantep, Turkey

Address of Correspondence:

Submitted for :Publication

Revised for: Publication

Accepted for Publication:

ORCID IDs of the authors: OI: 0000-0003-2263-8956,

MUB: 0000-0002-7008-8218,

$A K$ : 0000-0002-1223-9671,

RS: 0000-0002-6543-1130,
Mustafa Demir

Department of Obstetrics and Gynecology, Anka Hospital, 27590 Gaziantep, Turkey dr.mdemir35@gmail.com

22.03.2020

15.04 .2020

09.05 .2020

MD: 0000-0002-0130-0254

BY: 0000-0002-9458-2253

UCO: 0000-0002-1718-5422

ABT: 0000-0003-2981-1096

ST: 0000-0003-1251-3148

\section{Introduction}

Polycystic ovary syndrome (PCOS), myoma uteri and endometrioma are frequently seen gynecologic problems and all three diseases may cause infertility. Impaired endometrial receptivity is common infertility causing factors and may be related to these diseases. Endometrial receptivity might be hampered by abnormal cytokine levels, hormonal signaling, and epigenetic factors. For this reason, a better understanding of endometrial receptivity at the cellular and molecular level and identification of the role implantation markers in this process might help predict pregnancy outcomes and allow the use of assisted reproductive techniques to improve the success rate.

\begin{tabular}{|c|c|}
\hline \multirow{3}{*}{ 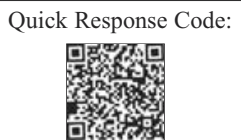 } & Access this article online \\
\hline & $\begin{array}{l}\text { Website: www.gorm.com.tr } \\
\text { e- mail: info@gorm.com.tr }\end{array}$ \\
\hline & DOI:10.21613/GORM.2020.1091 \\
\hline
\end{tabular}

How to cite this article: Demir M. Ince O. Yilmaz B. Barut MU. Ozturk UC. Kilic A. Turp AB. Sutcu R. Taysi S. Oxidative Stress in Endometrial Flushing Fluid of Patients with Polycystic Ovary Syndrome, Endometrioma and Uterine Leiomyoma: Comparison with Healthy Controls. Gynecol Obstet Reprod Med. 2020;26(2)123-129 
Recent biochemical and genetic studies on the pathogenesis of PCOS and endometriosis are focused on the single nucleotide polymorphisms affecting oxidative stress (OS) (1). These studies suggest that the maintenance of pro-antioxidant equilibrium is important for the physiology of reproduction (2), embryopathies and pregnancy (3). There is strong evidence for the pathogenesis of diseases leading to infertility. OS holds great importance as it is one of the most important factors negatively affecting in-vitro artificial reproductive techniques (ART) outcomes (4).

Oxidative stressrefers to elevated intracellular levels of reactive oxygen species (ROS) (5). ROS are permanently produced in the body during metabolic activities. To minimize the damage to cells, ROS are continuously eliminated by different intra - or extracellular antioxidative mechanisms $(6,7)$. Reduced antioxidative capacity and an increase in the production of ROS lead to OS, which is detrimental to cells (8). It is pointed out in the literature that ROS play a role in the pathogenesis of many diseases $(6,9)$.

For PCOS, myoma uteri and endometrioma patients, the effect of OS on endometrial receptivity for both natural fertility and assisted reproductive technique is an important open question. As a first step in answering this question, comparing OS levels in the endometrium of these diseases will help understand their OS-related etiology and the mechanisms behind infertility.

Recent studies use several OS markers to compare oxidative state but most studies compare them in serum. Both total antioxidant status (TAS) and total oxidant status (TOS) are reliable and sensitive indicators of the current oxidant-antioxidant situation in the body and are tested for a variety of medical situations and health problems (10). Lipid hydroperoxide $(\mathrm{LOOH})$ is an important marker of OS formed from unsaturated phospholipids, glycolipids and cholesterol. Ceruloplasmin $(\mathrm{Cp})$ is an acute-phase plasma protein with antioxidant property (11). On account of the complex formation with ferroportin I, the membrane-bound $\mathrm{Cp}$ found in astrocytes participates in regulation of iron levels in the prevention of free radical reactions (12). Finally, total sulfhydryl (-SH) groups are very important for maintaining the cellular redox status (11).

There are few studies in the existing literature comparing the oxidant-antioxidant situation in endometrium of gynecologic diseases and healthy patients. For this purpose, we compare the OS marker levels listed above (TAS, Cp and total SH indicating antioxidant state; TOS, LOOH and OSI indicating oxidant state) in endometrial flushing fluid of patients with PCOS, uterine leiomyoma, endometrioma, and healthy women.

\section{Material and Method}

This cross-sectional study was conducted between January
- June 2013 at Izmir Katip Celebi University Ataturk Education and Research Hospital. Patients were recruited from the outpatient gynecology and infertility clinics. The study was approved by the local ethics committee of the Izmir Katip Celebi University Faculty of Medicine (2013-177-178179). All subjects were informed about the research verbally and written informed consent was obtained from all. The Helsinki declaration was followed. The study was conducted with patients that were also part of another study (13). The current study focuses on the comparison of OS markers among healthy patients and patients with benign gynecological diseases, whereas the earlier study investigated endometrial receptivity marker levels of the same population.

Volunteers between 20-40 years-old with regular periods (between 21-34 day); diagnosed with PCOS, endometrioma or uterine myoma, having no intrauterine device, not using hormonal contraception or taking medications that may affect the endometrium and with the intellectual capacity to comprehend the information about the study and provide written consent were included in the study.

Being pregnant, smoking, having pelvic infection symptoms, having luteal phase serum progesterone levels $<3 \mathrm{ng} / \mathrm{dL}$, opting out of the study and any suspicion of endometrial pathology (endometrial polyps, submucous fibroids, etc.) were the exclusion criteria. The evaluation of these pathologies were made based on transvaginal ultrasound (TV-USG) (Medison SonoAce, AM Company Co. Ltd., South Korea) and saline infusion sonography (SIS) that were routinely performed on patients after endometrial fluid sampling.

In the study, the first group included 20 subjects with PCOS who were diagnosed according to Rotterdam criteria (14). The second myoma uteri group included 20 patients with at least one intramural myoma uteri with $3-10 \mathrm{~cm}$ diameter as measured on TV-USG. The third group included 19 endometrioma patients who satisfied all three of the following criteria: (i) pelvic pain, (ii) dysmenorrhea, (iii) at least one unilocular cyst larger than $3 \mathrm{~cm}$ on TV-USG with diffuse homogeneous ground-glass echoes due to probable hemorrhagic debris. Lastly, the control group included 20 otherwise healthy reproductive-aged women. The fertility state of the patients was not used as a criterion in defining the groups.

Sexual intercourse was prohibited until the sampling of the endometrial flushing fluid in that menstruation cycle. After the confirmation of ovulation based on blood progesterone levels at the implantation window, endometrial fluid sampling was carried out following a procedure similar to the saline infusion sonography technique. A bivalve disposable speculum was inserted into the vagina and a menstrual regulating cannula ( $4 \mathrm{~mm}$ diameter) was introduced into the uterine cavity through the cervical canal. A syringe was then used to instill $5 \mathrm{ml}$ of sterile saline into the uterine cavity. The uterine contents were aspirated quickly. The procedure was re- 
peated two times, after which the samples were collected in separate Eppendorf tubes, centrifuged and stored at $-80^{\circ} \mathrm{C}$. The subjects were kept under observation for about half an hour after endometrial fluid sampling.

After endometrial fluid samples were collected and centrifuged from all patients, $\mathrm{Cp}$ enzymatic activity was measured according to Erel's method (15). The level of the total SH of the serum samples were assayed according to Ellman's method (16). Serum LOOH levels were measured with the ferrous ion oxidation-xylenol orange (FOX-2) method (17). Measurement of plasma TOS levels were determined using a novel automated colorimetric measurement method developed by Erel (18). The results were recorded in micromolar hydrogen peroxide equivalent per liter ( $\mu$ mol H2O2 Eq/L). Endometrial flushing fluid TAS levels were measured using a novel automated colorimetric measurement method developed by Erel again (19). Results were recorded in mmol TroloxEq/L. The percent ratio of the TOS to TAS level was accepted as an oxidative stress index (OSI). To calculate this index, the unit of the TAS, mmolTrolox equivalent/1, was converted to $\mu \mathrm{mol}$ equivalent $/ \mathrm{l}$, and the OSI value was calculated based on the formula OSI $=((\mathrm{TOS}, \mu \mathrm{mol} / \mathrm{l}) /(\mathrm{TAS}, \quad(\mu \mathrm{mol}$ TroloxEquiv/l) $\times 100)(20)$.

For the statistical analysis, SPSS, Version 21.0 (SPSS Inc., Chicago, IL) was used. All values were reported as median, min-max and mean \pm SD. Normality was tested by ShapiroWilks and Levene's tests. The Kruskal-Wallis H test was used for comparison of the variables between the groups. $\mathrm{P}$ value $<0.05$ was considered as statistically significant.

\section{Results}

There were no major complications during or after the procedure regarding cervical or uterine bleeding, laceration or pelvic infection.

Table I reports the demographic and baseline characteristics of the patients. The average age of PCOS, uterine myoma, endometriosis and control group patients were 28.90, 37.25, 32.84 and 32.15 , respectively. The difference between endometrioma and the control group was not statistically significant. For all other two-group comparisons, the difference was significant. Mean body mass index $\left(\mathrm{kg} / \mathrm{m}^{2}\right)$ was the highest in PCOS group (26.65), lowest in endometrioma group (21.71; all $p<0.01$ compared to other three groups) and similar for uterine myoma (24.93) and control (24.92) groups. Mid-luteal phase serum progesterone levels $(\mathrm{ng} / \mathrm{mL})$ were similar in uterine myoma (9.61), PCOS (9.47) and control groups (8.75), while it was lower in a statistically significantly way in the endometrioma group $(6.26 ; p<0.01,0.05,0.05$, respectively). Moreover, both average gravida and parity values were lowest in the PCOS group and highest in the control group with a statistically significant difference between groups (Table I).

As shown in table II, and figure 1 and 2, markers indicating antioxidant state were quite similar in all 3 benign gynecologic diseases and control women ( $p=0.806$ for TAS, $p=0.156$ for $\mathrm{Cp}, p=0.328$ for $-\mathrm{SH}$ ). In a similar vein, markers indicating OS didn't differ significantly between the PCOS, myoma uteri, endometrioma and control groups (Table II). However, TOS values were the lowest in the control group $(0.12 \pm 0.04), \mathrm{LOOH}$ levels were the highest in endometrioma group (7.59 \pm 3.08$)$ and $p$-values were slightly over 0.05 ( $p=0.09$ and $p=0,087$, respectively).

Table I: Demographic and baseline data including pairwise comparisons

\begin{tabular}{|c|c|c|c|c|c|}
\hline & $\begin{array}{l}\text { PCOS } \\
(n=20)\end{array}$ & $\begin{array}{l}\text { Myoma uteri } \\
(n=20)\end{array}$ & $\begin{array}{l}\text { Endometrioma } \\
(\mathrm{n}=19)\end{array}$ & $\begin{array}{l}\text { Control } \\
(n=20)\end{array}$ & $p$ \\
\hline Age, (year) & $\begin{array}{l}29(20-38) \\
(28.90 \pm 5.45)^{a, b, e}\end{array}$ & $\begin{array}{l}38(32-40) \\
(37.25 \pm 2.73)^{\mathrm{b}, \mathrm{c}}\end{array}$ & $\begin{array}{l}34(20-40) \\
(32.84 \pm 6.62)\end{array}$ & $\begin{array}{l}34(22-39) \\
(32.15 \pm 5.18)\end{array}$ & 0.000 \\
\hline BMI, $\left(\mathrm{kg} / \mathrm{m}^{2}\right)$ & $\begin{array}{l}26(18.10-35.30) \\
(26.65 \pm 4.74)^{d}\end{array}$ & $\begin{array}{l}25(19.50-35) \\
(24.93 \pm 4.01)^{d}\end{array}$ & $\begin{array}{l}21.4(17.5-27.3) \\
(21.71 \pm 2.92)^{c}\end{array}$ & $\begin{array}{l}24.7(19-31.2) \\
(24.92 \pm 3.67)\end{array}$ & 0.002 \\
\hline Gravidity, (n) & $\begin{array}{l}0.5(0-1) \\
(0.50 \pm 0.51)^{\mathrm{e}, \mathrm{f}}\end{array}$ & $\begin{array}{l}2(0-5) \\
(1.75 \pm 1.52)^{f}\end{array}$ & $\begin{array}{l}1(0-4) \\
(0.97 \pm 1.22)^{f}\end{array}$ & $\begin{array}{l}3(2-8) \\
(3.75 \pm 1.77)\end{array}$ & 0.000 \\
\hline Parity, (n) & $\begin{array}{l}0(0-1) \\
(0.35 \pm 0.49)^{e, f}\end{array}$ & $\begin{array}{l}1(0-3) \\
(1.5 \pm 1.04)^{f}\end{array}$ & $\begin{array}{l}0(0-3) \\
(0.789 \pm 1.03)^{f}\end{array}$ & $\begin{array}{l}3(1-8) \\
(2.90 \pm 1.37)\end{array}$ & 0.000 \\
\hline $\begin{array}{l}\text { Progesteron, } \\
(\mathrm{ng} / \mathrm{mL})\end{array}$ & $\begin{array}{l}8.39(3.71-19) \\
(9.47 \pm 4.17)^{d}\end{array}$ & $\begin{array}{l}7.04(3.47-21.73) \\
(9.61 \pm 5.56)^{\mathrm{b}}\end{array}$ & $\begin{array}{l}4.6(3-14.49) \\
(6.26 \pm 3.57)^{\mathrm{a}}\end{array}$ & $\begin{array}{l}8.53(3.75-17.77) \\
(8.75 \pm 3.67)\end{array}$ & 0.035 \\
\hline
\end{tabular}

Values are presented as median (min-max) (mean $\pm S D) ; P C O S=$ Polycystic ovary syndrome; BMI = body mass index. p-values were calculated with Kruskal-Wallis $\mathrm{H}$ test. $p<0.05$ compared with control (a) and endometrioma (b). $p<0.01$ compared with control (c), endometrioma (d) and myoma uteri (e). $p<0.001$ compared with control (f). 
Table II: Comparison of total antioxidant status, total oxidant status, lipid hydroperoxide, ceruloplasmin, and sulfhydryl levels among groups

\begin{tabular}{|c|c|c|c|c|c|}
\hline & $\begin{array}{l}\text { PCOS } \\
(n=20)\end{array}$ & $\begin{array}{l}\text { Myoma uteri } \\
(n=20)\end{array}$ & $\begin{array}{l}\text { Endometrioma } \\
(n=19)\end{array}$ & $\begin{array}{l}\text { Control } \\
(n=20)\end{array}$ & $\mathrm{p}^{*}$ \\
\hline TAS (mmolTroloxEq/L) & $\begin{array}{l}0.04(0.01-0.38) \\
0.09 \pm 0.11\end{array}$ & $\begin{array}{l}0.04(0.01-0.70) \\
0.09 \pm 0.16\end{array}$ & $\begin{array}{l}0.03(0.01-0.46) \\
0.09 \pm 0.13\end{array}$ & $\begin{array}{l}0.04(0.01-0.58) \\
0.10 \pm 0.14\end{array}$ & 0.806 \\
\hline $\begin{array}{l}\text { Ceruloplasmin } \\
(\mathrm{U} / \mathrm{L})\end{array}$ & $\begin{array}{l}234.5(224.8-254.4) \\
235.6 \pm 7.4\end{array}$ & $\begin{array}{l}235.4(222.0-249.8) \\
235.0 \pm 7.7\end{array}$ & $\begin{array}{l}240.5(226.6-257.2) \\
240.8 \pm 8.9\end{array}$ & $\begin{array}{l}237.7(227.6-419.0) \\
246.0 \pm 41.3\end{array}$ & 0.156 \\
\hline $\begin{array}{l}\text { Sulfhydryl } \\
\text { (mmol/L) }\end{array}$ & $\begin{array}{l}0.11(0.10-0.23) \\
0.13 \pm 0.04\end{array}$ & $\begin{array}{l}0.11(0.10-0.37) \\
0.13 \pm 0.06\end{array}$ & $\begin{array}{l}0.11(0.09-0.24) \\
0.12 \pm 0.04\end{array}$ & $\begin{array}{l}0.11(0.08-0.24) \\
0.12 \pm 0.04\end{array}$ & 0.328 \\
\hline $\begin{array}{l}\text { TOS } \\
(\mu \mathrm{mol} \mathrm{H} 2 \mathrm{O} 2 \mathrm{Eq} / \mathrm{L})\end{array}$ & $\begin{array}{l}10.88(7.45-73.45) \\
14.92 \pm 14.44\end{array}$ & $\begin{array}{l}8.27(7.37-42.30) \\
12.01 \pm 9.09\end{array}$ & $\begin{array}{l}12.63(7.56-82.54) \\
16.44 \pm 16.98\end{array}$ & $\begin{array}{l}8.05(7.39-93.75) \\
14.70 \pm 19.31\end{array}$ & 0.090 \\
\hline $\begin{array}{l}\text { Lipid hydroperoxide } \\
(\mu \mathrm{mol} / \mathrm{L})\end{array}$ & $\begin{array}{l}6.60(6.00-18.40) \\
7.45 \pm 2.71\end{array}$ & $\begin{array}{l}6.22 \quad(5.97-12.25) \\
6.85 \pm 1.61\end{array}$ & $\begin{array}{l}6.89(6.01-19.79) \\
7.59 \pm 3.08\end{array}$ & $\begin{array}{l}6.30(5.87-22.61) \\
7.32 \pm 3.68\end{array}$ & 0.087 \\
\hline $\begin{array}{l}\text { OSI } \\
\text { (TOS/TAS) }\end{array}$ & $\begin{array}{l}26.01(6.57-75.65) \\
28.34 \pm 18.82\end{array}$ & $\begin{array}{l}21.56(4.45-64.46) \\
26.99 \pm 17.94\end{array}$ & $\begin{array}{l}36.60(4.73-68.56) \\
35.73 \pm 17.90\end{array}$ & $\begin{array}{l}27.81(6.86-51.20) \\
26.99 \pm 14.99\end{array}$ & 0.312 \\
\hline
\end{tabular}

TAS: Total antioxidant status, TOS: Total oxidant status, OSI: oxidative stress index. PCOS: Polycystic ovary syndrome. Values are presented as mean $\pm S D, *$ Kruskal-Wallis $H$ test
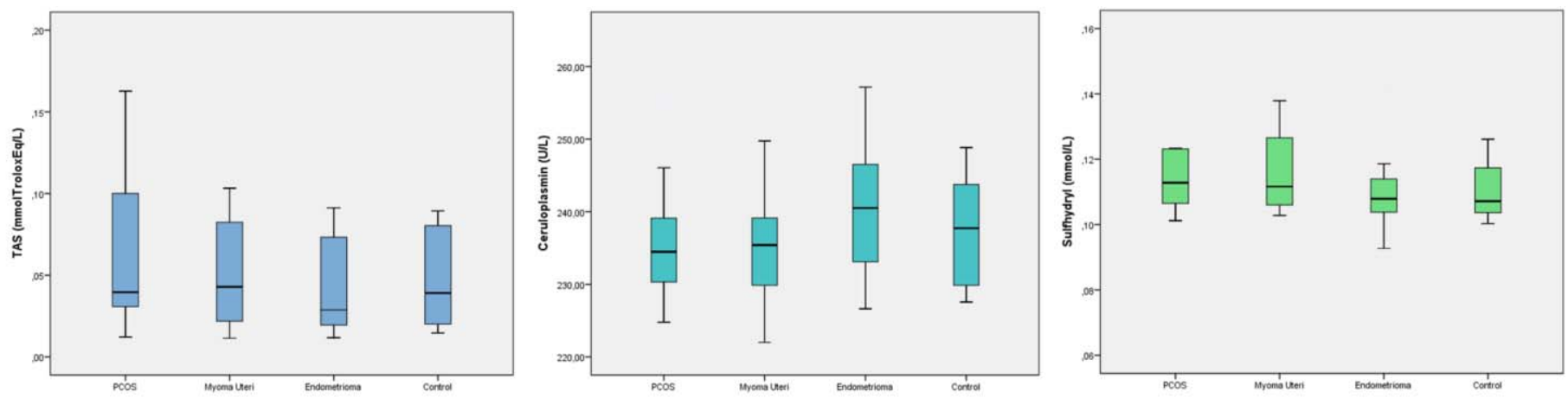

Figure 1: Comparison of antioxidant state related marker (Total antioxidant status, ceruloplasmin, and sulfhydryl) levels among groups
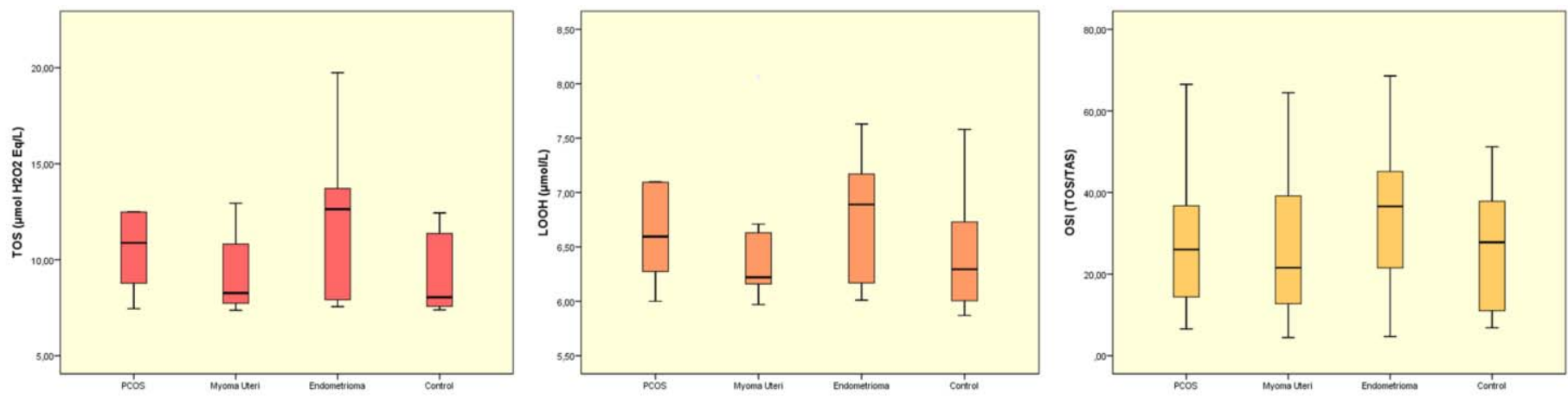

Figure 2: Comparison of oxidant state related marker (Total oxidant status, Lipid hydroperoxide, and oxidative stress index) levels among groups

\section{Discussion}

The aim of this cross-sectional study was to evaluate the
OS levels in endometrial flushing fluid of patients with PCOS, endometrioma, uterine leiomyoma and in healthy women. The study did not find any statistically significant difference in 
TAS, Cp, total-SH, TOS, LOOH and OSI levels between patients with PCOS, endometrioma, uterine leiomyoma, and healthy controls.

Oxidative stress is a state of imbalance between the production of free radicals during normal aerobic metabolism or intra- and extracellular pathologic events and the ability of the body to counteract their harmful effects through neutralization by antioxidants (1). It has critical roles in the normal functioning of the female reproductive system (4). The effect of OS on male infertility has been well-established, but its impact on female reproductive disorders is an open question. ROS and reactive nitrogen species (RNS) may negatively affect embryo implantation and induce reproductive disorders (21).

Oxidative stress and the impaired antioxidant system has been proposed as a potential factor involved in the pathophysiology of diverse disease states and in the development of female reproductive diseases such as endometriosis and PCOS (4). TAS and TOS have been investigated as potential causes for a wide range of medical issues. Recent biochemical and genetic studies on the pathogenesis of PCOS and endometriosis were focused on the Single Nucleotide Polymorphisms (SNPs) affecting OS (22).

Polycystic ovary syndrome is the most common endocrinopathy in women of reproductive age with a prevalence rate of 5-10\% and can lead to conditions such as infertility, recurrent spontaneous abortions. In the existing literature, increased oxidative state is evaluated by circulating markers of patients with PCOS. Relying on this approach, Hilali et al. (2013) found increased TOS and OSI levels (23) and Zuo et al. (2016) found increased malondialdehyde, superoxide dismutase and glutathione peroxidase levels in the serum of the women with PCOS (24). Torun et al. found PCOS patients without metabolic syndrome and insulin resistance had increased LOOH, TOS levels and OSI ratio indicating increased OS in their serum (25). Zhang et al. in 2017 found elevated TOS and OSI levels in patients with different clinical phenotypes of PCOS, compared to controls (26). Finally, Turan et al. found elevated OS marker levels such as malondialdehyde and glutathione peroxidase in infertile PCOS patients compared to non-infertile PCOS group (27). As a contribution to this literature, the current study is the first to measure TAS, TOS, $\mathrm{LOOH}, \mathrm{Cp}$ and -SH levels in the endometrial flushing fluid during implantation period and finds that the levels are not significantly different in PCOS patients than the control group.

Our second study group was women with endometrioma. Despite limited information about the etiology of endometriosis, it is conjectured that in an oxidant state, ROS might increase the growth and adhesion of endometrial cells in the peritoneal cavity (28). Previous studies have reported the close relationship between OS and endometriosis (29). Several studies have reported the elevated levels of OS markers and reduced levels of total antioxidant capacity in serum and follicular fluid of women with endometriosis (30). Turkyilmaz et al. found higher plasma disulfide and lower Cp levels in advanced stage endometriosis patients but the differences were statistically insignificant (31). They concluded that the use of antioxidants may become valuable treatment modalities for endometriosis in the future. Similarly, another recent study found higher TOS, OSI and Cp and lower TOS and HDL levels in women with advanced-stage of endometriosis than in the control groups (32). Nonetheless, conflicting results were reported in further studies with large patient numbers, which failed to demonstrate an antioxidant or oxidant balance $(29,30)$. To the best of our knowledge, there is only one study investigating oxidative state in eutopic endometria of women with endometriosis, where authors reported that the levels of malondialdehyde and total sulfhydryl groups and glutathione peroxidase activity were similar in the eutopic and ectopic endometria, whereas the superoxide dismutase activity was found to be significantly higher in the latter ectopic endometrial tissue (33).

Reactive oxygen species may be involved in the regulation of the expression of genes encoding cytokines and cellular adhesion molecules implicated in the pathogenesis of endometriosis (34). Endometrial receptivity might be hampered by oxidant state in the eutopic endometrium of endometriosis patients. To the best of our knowledge, there is only one study investigating endometrial oxidative status in endometriosis patients (33). However, our study was the first to study this question with the non-invasive endometrial flushing method. As it was the case with the PCOS group, for all 6 oxidative markers that we studied, there was no statistically significant difference between patients with endometrioma and control groups in the uterine irrigation fluid during the implantation window.

Recent studies suggest that intramural or submucosal leiomyomas affect fertility through their impact on overlying endometrial tissue and endometrial receptivity (35). Therefore, we chose the women with leiomyoma as the third group to investigate the oxidative state in its endometrium. There are a limited number of studies investigating the oxidative state in the endometrium of myoma uteri patients, most of which are by Pejic et al. (36,37). As far as we know, higher LOOH levels might reflect the impaired oxidant/antioxidant balance in favor of OS (38) and Pejic et al. found insignificant moderate elevation of $\mathrm{LOOH}$ in plasma of myoma uteri patients compared to controls. The same study also compared LOOH levels in endometrial biopsy specimens, but there was no control group. It found that the LOOH level was significantly lower in myoma subjects' relative to patients with simple or complex hyperplasia and adenocarcinoma (39). Nayki et al. (2017) compared oxidative state in endometrial biopsy specimens of benign gynecologic diseases, and the differences in antioxidant enzyme activities, TAS and TOS between myoma and control groups were insignificant (40). There was 
no other study in the literature investigating mid secretory phase endometrial flushing fluid TAS and TOS levels. This study is the first in the literature to tackle this question and finds that mean TAS, TOS, LOOH, Cp and total-SH levels were similar in myoma uteri and control women.

The results of the current study offer a new perspective on the oxidative state in the endometrium of women with PCOS, myoma uteri and endometrioma patients. In the existing literature, there is consensus on the presence of increased systemic OS in plasma of these women compared to healthy patients. However, the results of this study do not support the findings of previous literature. On the other hand, this finding should be interpreted with caution, as there are some limitations of the present study as discussed below.

One limitation of the current study those baseline demographic findings of different groups were not similar. A second concern is the use of the uterine flushing technique to analyze the endometrial receptivity markers. This method has some advantages and disadvantages compared to immunohistochemistry using the endometrial tissue of the volunteers. Arguably, uterine flushing was studied in the literature less commonly; nevertheless, it is less invasive and more acceptable to the patients.

In conclusion, this study provides evidence that endometrial flushing fluid total oxidant and antioxidant status, $\mathrm{LOOH}$, $\mathrm{Cp}$ and total-SH levels did not differ between patients with polycystic ovary syndrome, endometrioma, myoma uteri, and control women. Further studies with larger sample sizes, more homogenous patients and different endometrial sampling techniques are needed to test whether endometrial oxidative stress may be affected in infertile women with different etiology.

Funding :Authors received no grant for this research. Conflict of interest: Authors report no conflict of interest. Acknowledgement : None

Author Contributions: MD: Conception and design, Acquisition of data, Drafting of the manuscript. BY: Conception and design, Drafting of the manuscript, Supervision. OI: Analysis and Interpretation of data, Drafting of the manuscript, Statistical analysis. MUB: Drafting of the manuscript, Supervision. UCO: Writing and Drafting of the manuscript. AK: Analysis and Interpretation of data, Drafting of the manuscript. AB: Turp writing and drafting of the manuscript. RS: Acquisition of data, Biochemical analaysis. ST: Conception and design, Analysis and Interpretation of data, Supervision.

\section{References}

1. Yamamoto Y. Role of active oxygen species and antioxidants in photoaging. J Dermatol Sci. 2001;27 Suppl 1:S1-4.

2. Agarwal A, Saleh RA, Bedaiwy MA. Role of reactive oxygen species in the pathophysiology of human repro- duction. Fertil Steril. 2003;79(4):829-43.

3. Sharma RK, Agarwal A. Role of reactive oxygen species in gynecologic diseases. Reprod Med Biol. 2004;3(4): 177-199.

4. Agarwal A, Gupta S, Sharma R. Oxidative stress and its implications in female infertility-a clinician's perspective. Reprod Biomed Online. 2005;11(5):641-50.

5. Schieber M, Chandel NS. ROS function in redox signaling and oxidative stress. Curr Biol. 2014;24(10):R453-62.

6. Taysi S, Cikman O, Kaya A, Demircan B, Gumustekin K, Yilmaz A, et al. Increased oxidant stress and decreased antioxidant status in erythrocytes of rats fed with zinc-deficient diet. Biol Trace Elem Res. 2008;123(1-3):161-7.

7. Baysal E, Gulsen S, Aytac I, Celenk F, Ensari N, Taysi S, et al. Oxidative stress in otosclerosis. Redox Rep. 2017;22(5):235-9.

8. Aksoy H, Taysi S, Altinkaynak K, Bakan E, Bakan N, Kumtepe Y. Antioxidant potential and transferrin, ceruloplasmin, and lipid peroxidation levels in women with preeclampsia. J Investig Med. 2003;51(5):284-7.

9. Akinci S, Özcan HC, Balat Ö, Uğur MG, Öztürk E, Taysi $\mathrm{S}$, et al. Assessment of $\beta$-hydroxydeoxyguanosine levels in patients with preeclampsia: a prospective study. Clin Exp Obstet Gynecol. 2017;44(2):226-9.

10. Geyik S, Altunisik E, Neyal AM, Taysi S. Oxidative stress and DNA damage in patients with migraine. J Headache Pain. 2016;17:10

11. Zengin S, Behcet A, Karta S, Can B, Orkmez M, Taskin A, et al. An assessment of antioxidant status in patients with carbon monoxide poisoning. World J Emerg Med. 2014;5(2):91-5.

12. Patel BN, Dunn RJ, Jeong SY, Zhu Q, Julien JP, David S. Ceruloplasmin regulates iron levels in the CNS and prevents free radical injury. J Neurosci. 2002;22(15):657886.

13. Demir M, Ince O, Ozkan B, Kelekci S, Sutcu R, Yilmaz B. Endometrial flushing alphaVbeta3 integrin, glycodelin and PGF2alpha levels for evaluating endometrial receptivity in women with polycystic ovary syndrome, myoma uteri and endometrioma. Gynecol Endocrinol. 2017; 33(9):716-720.

14. Rotterdam ESHRE/ASRM-Sponsored PCOS Consensus Workshop Group. Revised 2003 consensus on diagnostic criteria and long-term health risks related to polycystic ovary syndrome. Fertil Steril. 2004;81(1):19-25.

15. Erel O. Automated measurement of serum ferroxidase activity. Clin Chem. 1998;44(11):2313-9.

16. Ellman GL. Tissue sulfhydryl groups. Arch Biochem Biophys. 1959;82(1):70-7.

17. Nourooz-Zadeh J. Ferrous ion oxidation in presence of xylenol orange for detection of lipid hydroperoxides in plasma. Methods Enzymol. 1999;300:58-62. 
18. Erel O. A new automated colorimetric method for measuring total oxidant status. Clin Biochem. 2005;38(12): 110311.

19. Erel O. A novel automated direct measurement method for total antioxidant capacity using a new generation, more stable ABTS radical cation. Clin Biochem. 2004;37(4): 277-85.

20. Harma M, Harma M, Erel O. Oxidative stress in women with preeclampsia. Am J Obstet Gynecol. 2005;192(2): 656-7; author reply 657 .

21. Pasqualotto EB, Agarwal A, Sharma RK, Izzo VM, Pinotti JA, Joshi NJ, et al. Effect of oxidative stress in follicular fluid on the outcome of assisted reproductive procedures. Fertil Steril. 2004;81(4):973-6.

22. Yeon Lee J, Baw C-K, Gupta S, Aziz N, Agarwal A. Role of oxidative stress in polycystic ovary syndrome. Current Women's Health Reviews. 2010;2(6):96-107.

23. Hilali N, Vural M, Camuzcuoglu H, Camuzcuoglu A, Aksoy N. Increased prolidase activity and oxidative stress in PCOS. Clin Endocrinol (Oxf). 2013;79(1):105-10.

24. Zuo T, Zhu M, Xu W. Roles of oxidative stress in polycystic ovary syndrome and cancers. Oxid Med Cell Longev. 2016;2016:8589318.35.

25. Torun AN, Vural M, Cece H, Camuzcuoglu H, Toy H, Aksoy N. Paraoxonase-1 is not affected in polycystic ovary syndrome without metabolic syndrome and insulin resistance, but oxidative stress is altered. Gynecol Endocrinol. 2011;27(12):988-92.36.

26. Zhang R, Liu H, Bai H, Zhang Y, Liu Q, Guan L, et al. et al. Oxidative stress status in Chinese women with different clinical phenotypes of polycystic ovary syndrome. Clin Endocrinol (Oxf). 2017;86(1):88-96.

27. Turan V, Sezer ED, Zeybek B, Sendag F. Infertility and the presence of insulin resistance are associated with increased oxidative stress in young, non-obese Turkish women with polycystic ovary syndrome. J Pediatr Adolesc Gynecol. 2015;28(2):119-23.

28. Jackson LW, Schisterman EF, Dey-Rao R, Browne R, Armstrong D. Oxidative stress and endometriosis. Hum Reprod. 2005;20(7):2014-20.

29. Bedaiwy MA, Falcone T, Sharma RK, Goldberg JM, Attaran M, Nelson DR, et al. Prediction of endometriosis with serum and peritoneal fluid markers: a prospective controlled trial. Hum Reprod. 2002;17(2):426-31.

30. Wang Y, Sharma RK, Falcone T, Goldberg J, Agarwal A.
Importance of reactive oxygen species in the peritoneal fluid of women with endometriosis or idiopathic infertility. Fertil Steril. 1997;68(5):826-30.

31. Turkyilmaz E, Yildirim M, Cendek BD, Baran P, Alisik M, Dalgaci F, et al. Evaluation of oxidative stress markers and intra-extracellular antioxidant activities in patients with endometriosis. Eur J Obstet Gynecol Reprod Biol. 2016;199:164-8.

32. Turgut A, Özler A, Görük NY, Tunc SY, Evliyaoglu O, Gül T. Copper, ceruloplasmin and oxidative stress in patients with advanced-stage endometriosis. Eur Rev Med Pharmacol Sci. 2013;17(11):1472-8.

33. Oner-Iyidoğan Y1, Koçak H, Gürdöl F, Korkmaz D, Buyru F. Indices of oxidative stress in eutopic and ectopic endometria of women with endometriosis. Gynecol Obstet Invest. 2004;57(4):214-7.

34. Van Langendonckt A, Casanas-Roux F, Donnez J. Oxidative stress and peritoneal endometriosis. Fertil Steril. 2002;77(5):861-70.48.

35. Rackow BW, Taylor HS. Submucosal uterine leiomyomas have a global effect on molecular determinants of endometrial receptivity. Fertil Steril. 2010;93(6):2027-34.

36. Pejić S, Todorović A, Stojiljković V, Gavrilović L, Popović N, Pajović SB. Antioxidant status in women with uterine leiomyoma: relation with sex hormones. An Acad Bras Cienc. 2015 Sep;87(3):1771-82.

37. Pejić S, Todorović A, Stojiljković V, Kasapović J, Pajović SB. Antioxidant enzymes and lipid peroxidation in endometrium of patients with polyps, myoma, hyperplasia and adenocarcinoma. Reprod Biol Endocrinol. 2009; $7: 149$.

38. Ghiselli A, Serafini M, Natella F, Scaccini C. Total antioxidant capacity as a tool to assess redox status: critical view and experimental data. Free Radic Biol Med. 2000; 29(11):1106-14.

39. Pejić S, Todorović A, Stojiljković V, Cvetković D, Lucić N, Radojicić RM, et al. Superoxide dismutase and lipid hydroperoxides in blood and endometrial tissue of patients with benign, hyperplastic and malignant endometrium. An Acad Bras Cienc. 2008;80(3):515-22.

40. Nayki C, Nayki U, Gunay M, Kulhan M, Cankaya M, Humeyra Taskin Kafa A, et al. Oxidative and antioxidative status in the endometrium of patients with benign gynecological disorders. J Gynecol Obstet Hum Reprod. 2017; 46(3):243-7. 